\title{
Analisa Peracangan Prototype Arsip Surat di Dinas Lingkungan Hidup Kota Madiun
}

\author{
Tobi Dwiongko Saputro ${ }^{1}$, Farras Raihan Al-ayyubi ${ }^{2}$ \\ ${ }^{1}$ Program Studi Sistem Informasi, Universitas PGRI Madiun,Jl. Setia Budi No. 85, Madiun,63118 \\ E-mail: obyds59@gmail.com \\ ${ }^{2}$ Program Studi Sistem Informasi, Universitas PGRI Madiun,Jl. Setia Budi No. 85, Madiun,63118 \\ E-mail: farrasraihan88@gmail.com
}

\begin{abstract}
The Madiun Environment Agency in the Field of Environmental Pollution Control has problems with archiving letters, managing incoming and outgoing letters in the Field of Environmental Damage Pollution Control still using a convental way which means that the filing of letters still uses the agenda book. It can cause damage to the agenda book and in archiving takes a long time. Mail archive information system will help make it easier for admins to manage mail archives quickly, precisely and efficiently. With the design of this prototype, it is expected that there will be no more problems in recording or managing incoming and outgoing letters at the Madiun Environment Agency. The purpose of this research is to analyze and design a prototype of The Mail Archive Information System, using unified modeling language (UML) system modeling methods. The system is designed with the feature of managing incoming mail data, managing outgoing mail data and managing incoming and outgoing mail data reports. The need to add features to print incoming and outgoing mail in order to be created for annual reports in their respective fields. This prototype information system needs to be developed and implemented at the Madiun Environment Agency as a solution to the archives of incoming and outgoing mail.
\end{abstract}

Keywords - : Archive; UML; Prototype; Analysis.

\section{PENDAHULUAN}

Di era digital 4.0 hampir semua organisasi menggunakan sarana teknologi informasi untuk melaksanakan kegiatannya. Banyak perusahaan yang tersingkir akibat adanya pergeseran penggunaan sarana informasi dan teknologi karena terlambat dalam berinovasi. Sistem informasi adalah suatu sistem dalam suatu organisasi yang mempertemukan kebutuhan pengolahan transaksi harian yang mendukung fungsi operasi organisasi yang bersifat manajerial dengan kegiatan strategi dari suatu organisasi untuk dapat menyediakan kepada pihak luar tertentu dengan informasi yang diperlukan untuk pengambilan keputusan. Definisi sistem informasi menurut Abdul Kadir adalah "sistem informasi adalah kerangka kerja yang mengkoordinasikan sumber daya (manusia, komputer) untuk mengubah masukan (input) menjadi keluaran (informasi), guna mencapai sasaran-sasaran perusahaan". Peranan sistem informasi adalah membantu mengendalikan dan mengorganisasikan aktivitas aktivitas dari sub sistem - sub sistem dalam organisasi sehingga membantu organisasi tersebut dalam mencapai tujuannya (Lipursari, 2012).

Teknologi saat ini semakin berkembang dengan pesat, sehingga menyebabkan segala aspek manusia selalu dihubungkan dengan perkembangan tekonologi tersebut. Pengaruh dari perkembangan teknologi tersebut bias ditasakan berbagai bidang baik dari bidang akademik maupun non-akademik. Manfaat yang bisa dirasakan dari perkembangan teknologi yaitu pengolahan data yang bias dilakukan secara tepat, cepat, dan akurat. Dinas Lingkungan Hidup Kota Madiun merupakan Dinas Pemerintah yang berlokasi di Jalan Salak III No 7A, Kota Madiun. Arsip salah satu hal yang sangat penting di Dinas Lingkungan Hidup Kota Madiun. Semakin banyaknya surat masuk dan surat keluar membuat Staff TU dan bidang lainnya mengalami masalah, seperti kebutuhan tempat untuk pengarsipan surat masuk dan surat keluar, menjaga keamanan surat masuk dan surat keluar agar tidak hilang atau rusak, dan lamanya mencari arsip surat masuk dan surat keluar yang dibutuhkan. Berdasarkan masalah yang ada maka dalam kerja praktik ini penulis mencoba merancang dan membangun aplikasi arsip surat masuk dan keluar berbasis web guna mempermudah dalam mengakses dan mengelola arsip surat masuk dan surat keluar pada Dinas Lingkungan Hidup Kota Madiun yang saat ini masih menggunakan manual yang disimpan dan ditulis pada buku agenda. Dalam perancangan aplikasi ini menggunakan model prototype. Prototype adalah salah satu model sederhana pembuatan software yang dimana mengijinkan pengguna memiliki suatu gambaran awal atau dasar tentang program serta melakukan pengujian awal yang di dasarkan pada konsep model kerja. Protoype sendiri terdapat 4 proses pembuatannya yaitu analisis kebutuhan sistem, desain sistem, pengujian sistem, dan implementasi. Adapun terdapat alat perancangan sistemnya seperti Use Case Diagram yaitu permodelan untuk kelakuan sistem informasi yang akan dibuat, Class Diagram yaitu hubungan antar kelas didalam model desain dari suatu sistem, Activity Diagram yaitu menggambarkan aliran kerja atau aktivitas dari sebuah sistem, Flowchart yaitu peralatan yang digunakan untuk menggambarkan proses sistem secara rinci. Dengan adanya aplikasi ini 
diharapkan dapat mempermudah Staff TU dan bidang lainya dalam mengakses dan mengelola arsip surat masuk dan surat keluar, sehingga dapat menjadi acuan atau sumber informasi yang akurat bagi Dinas Lingkungan Hidup Kota Madiun dalam proses pengambilan keputusan, dan tidak lagi kesulitan dalam pencarian arsip surat masuk dan keluar, surat hilang ataupun rusak.

\section{METODE PENELITIAN}

\section{A. Tempat Penelitian}

Lokasi Penelitian berlokasi di J1. Salak No.7A Kota Madiun, Jawa Timur 63131

\section{B. Alur Penelitian}

Penelitian ini meliputi pengumpulan data Model perancangan sistem, prototype adalah adalah model kerja dasar dari pengembangan sebuah program (software) atau perangkat lunak. Prototipe dalam Bahasa Inggris "prototype" disebut juga dengan purwarupa. Prototipe biasanya dibuat sebagai model untuk tujuan demonstrasi atau sebagai bagian dari proses pengembangan atau pembuatan sebuah software ( Danny Pratama, 2017 )

Adapun susunan dalam metode ini yaitu:

\section{Pengumpulan Data}

Tahap pengumpulan data yang dibutuhkan dilakukan dengan cara melakukan 2 hal, antara lain :

a) Penelitian Lapangan

Pada penelitian ini, penulis mengumpulkan data dengan cara melakukan pengamatan dan interview atau wawancara dengan pegawai pada Dinas Lingkungan Hidup Kota Madiun sehingga mendapat data yang di perlukan untuk merancang aplikasi arsip surat masuk dan keluar tersebut.

b) Penelitian Kepustakaan

Pada penelitian ini, penulis memanfaatkan refrensi dari jurnal-jurnal di Google Schoolar yang sesuai dengan rumusan masalah sehingga dapat membantu penyelasain masalah dalam perancangan dan penyusunan tinjuan pustaka.

\section{Model Perancangan Sistem}

a) Prototyping

Perancangan sistem ini menggunakan model prototyping. Prototyping adalah proses yang digunakan untuk membantu pengembangan perangkat lunak dalam membentuk model dari perangkat lunak yang dibuat. (Fajrianto, 2017). Metode ini dilakukan secara bertahap, yaitu dengan mengembangkan suatu prototype yang sederhana terlebih dahulu baru kemudian dikembangkan dari waktu ke waktu sampai perangkat lunak selesai dikembangkan.

b) Tahapan Model Prototyping

Prototyping dimulai dengan pengumpulan kebutuhan, melibatkan pengembang dan pengguna sistem untuk menentukan tujuan, fungsi dan kebutuhan operasional sistem. Mengumpulkan kebutuhan melibatkan pertemuan antara pengembang dan pengguna untuk menentukan keseluruhan tujuan dibuatnya perangkat lunak, mengidentifikasi kebutuhan berupa garis besar kebutuhan dasar dari sistem yang dibuat. Desain berfokus pada representasi dari aspek perangkat lunak dari suduk pengguna; ini mencakup input, proses dan format output. Desain mengarah ke perancangan prototype, prototype dievaluasi oleh pengguna dan bagian analisis desain dan digunakan untuk menyesuaikan kebutuhan perangkat lunak yang akan dikembangkan.

Berikut gambar tahapan model prototype :

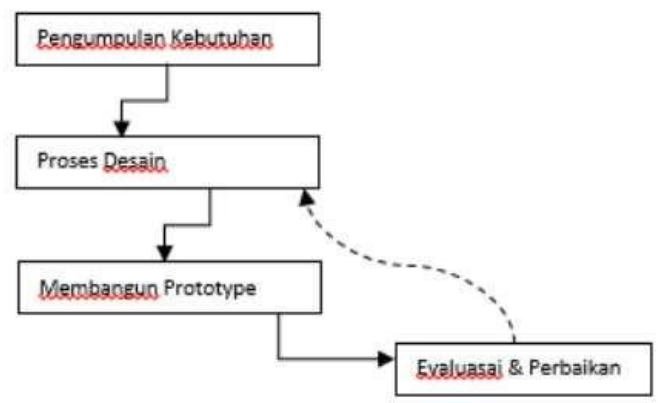

Gambar 1. Tahapan Model Prototype 
Gambaran umum yang dikerjakan

1. Perancangan Flowchart Jika login sudah valid maka admin dapat mengakses sistem program arsip surat, untuk kemudian melakukan tugasnya sebagai admin program seperti input data surat masuk, input data surat keluar, Serta kemudian dapat menyimpan data dari surat masuk dan surat keluar. Flowchart adalah t (Diagram Alir) atau di sebut Flowchart merupakan bagan (Chart) yang mengarahkan alir (flow) di dalam prosedur atau program sistem secara logika. Flowchart adalah cara untuk menjelaskan tahap-tahap pemecahan masalah dengan merepresentasikan simbolsimbol tertentu yang mudah dipahamii, mudah digunakan dan standar. (Syamsiah, 2019)
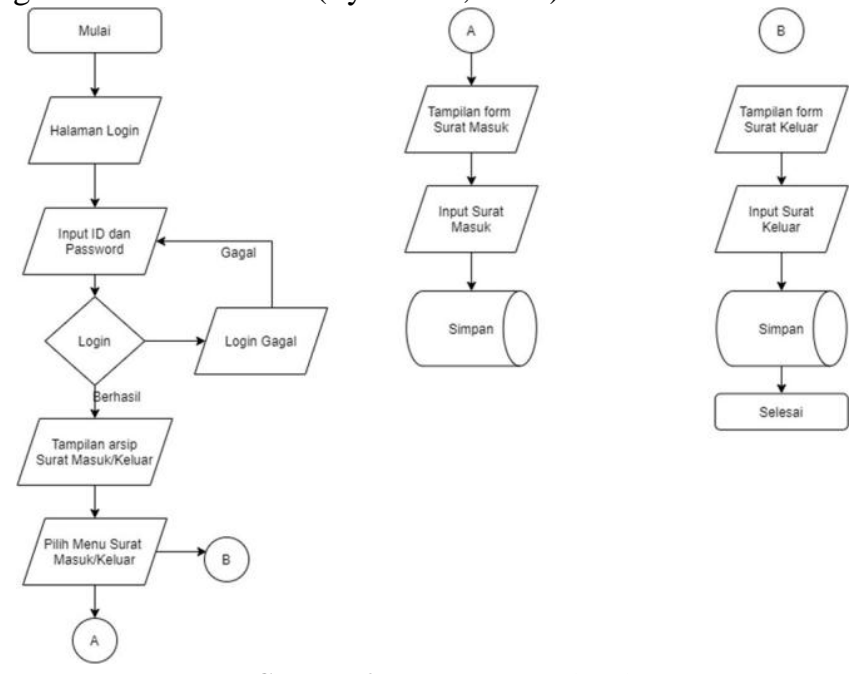

Gambar 2. Perancangan Flowchart

2. Use Case diagram digunakan untuk menggambarkan atau menjelaskan secara ringkas siapa (aktor) yang menggunakan sistem dan apa saja yang bisa dilakukannya (aktor). Menurut (Whitten dan Bentley, 2009). Use Case diagram adalah sebuah diagram yang mendeskripsikan interaksi antara sistem dengan bagian eksternal dari sistem serta dengan pengguna. Model perancangan Use Case ini bertujuan untuk menggambarkan perilaku masing- masing aktor yang saling terhubung dengan sistem (Chairul, 2019).

3. Perancangan Class Diagram, Class Diagram merupakan hubungan antar kelas dan penjelasan detail tiap-tiap kelas didalam model desain dari suatu sistem, juga memperlihatkan aturan-aturan dan tanggung jawab entitas yang menentukan perilaku sistem. Berikut ini perancangan class diagram Arsip Surat :

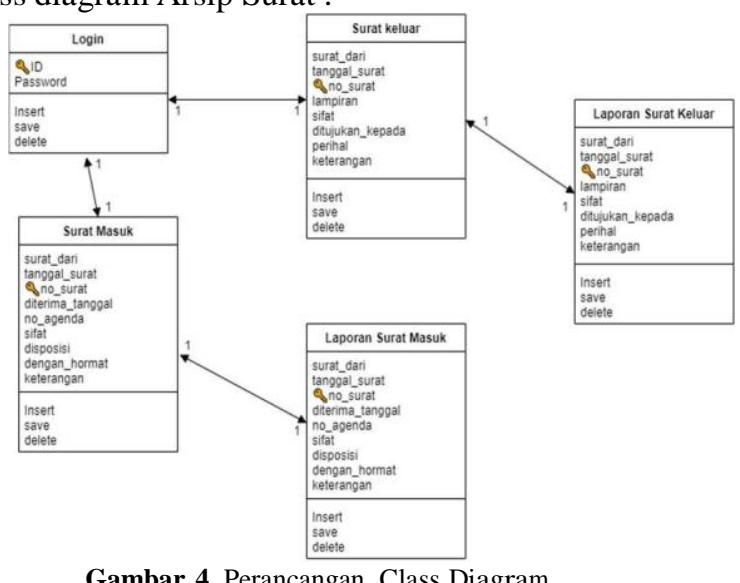

III.III. HASIL DAN PEMBAHASAN

\section{A. Analisa Kebutuhan}

Berdasarkan hasil wawancara pada Admin TU Dinas Lingkungan Hidup Kota Madiun, Sistem Pengarsipan surat masih dilakukan secara konvensional menggunakan buku agenda sehingga bisa rentan rusak buku agenda tersebut dan data surat masuk maupun surat keluar bisa hilang. Dengan adanya masalah tersebut penulis membuat sebuah perancangan prototype sistem arsip surat yang akan mempermudah Admin mengelola data surat masuk maupun surat keluar . 


\section{B. Perancangan Prototype}

Prototype adalah sebuah metode pengembangan software yang banyak digunakan pengembang agar dapat saling berinteraksi dengan user selama proses pembuatan sistem.

\section{Halaman Form Login}

Form ini untuk melakukan proses login untuk masuk kedalam menu utama arsip surat, yang hanya diperuntukkan untuk petugas. Petugas harus menginputkan username dan password dengan benar pada textbox yang telah disediakan. Pada saat tombol login ditekan, sistem akan mengecek username dan password yang telah tersimpan di database. Jika data username dan password benar maka user akan masuk kedalam sistem, sebaliknya jika username dan password salah maka tidak akan masuk sistem.

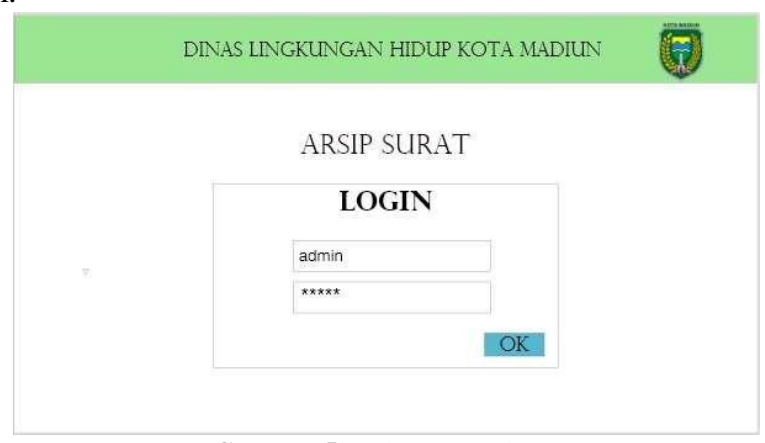

Gambar 5. Halaman Login

\section{Halaman Form Surat Masuk}

Setelah user berhasil login petugas atau user tersebut langsung bisa menginputkan surat masuk. Di halaman utama tersebut terdapat 4 bidang yang bisa dipilih, disini penulis memilih dan memfokuskan pada bidang 2 (Pengendalian Pencemaran dan Kerusakan Lingkungan Hidup).

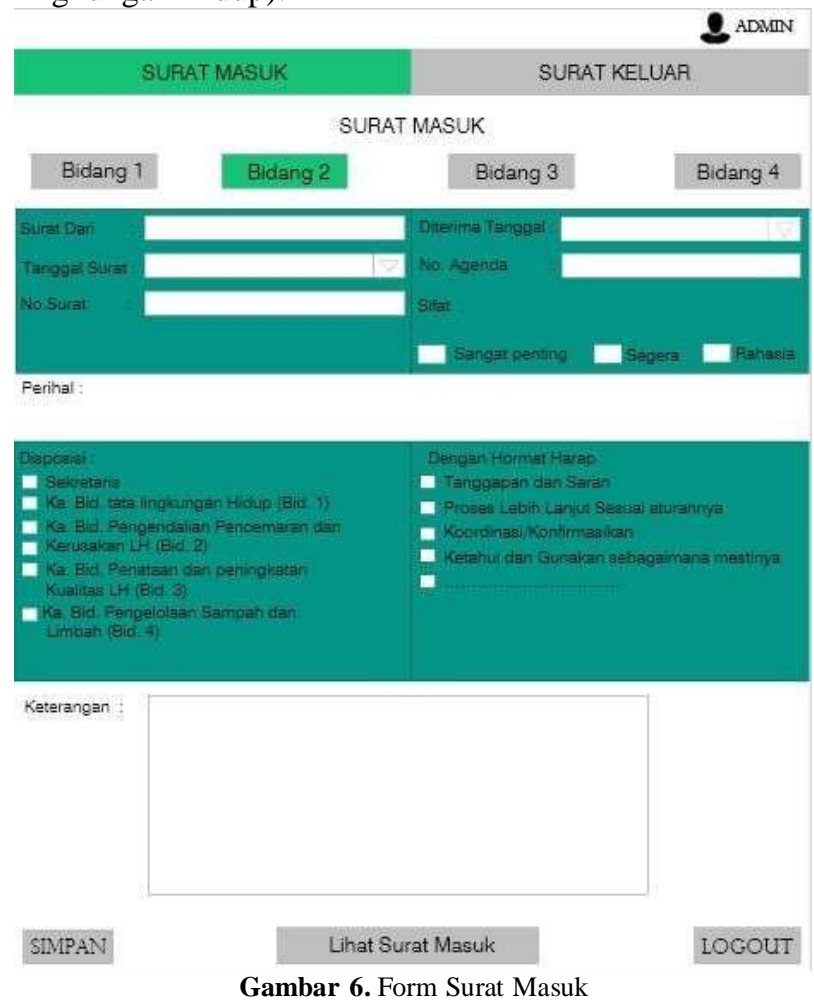




\section{Form Tabel Laporan Surat Masuk}

Form ini adalah tabel dari semua hasil penginputan di surat masuk.

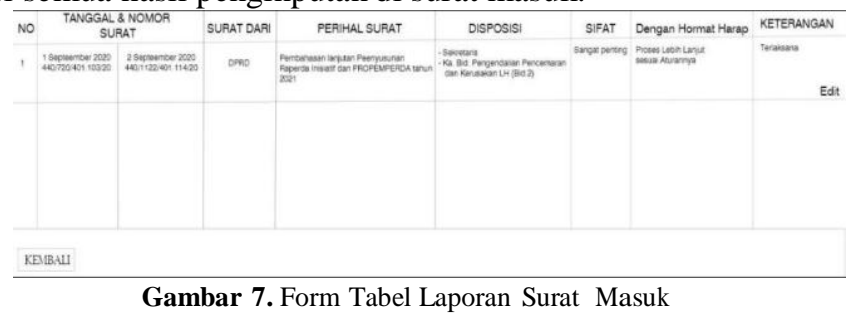

\section{Form Menu Edit Surat Masuk}

Pada form tabel laporan surat masuk tadi terdapat menu edit yang digunakan untuk memperbaiki surat masuk jika ada kesalahan penginputan.
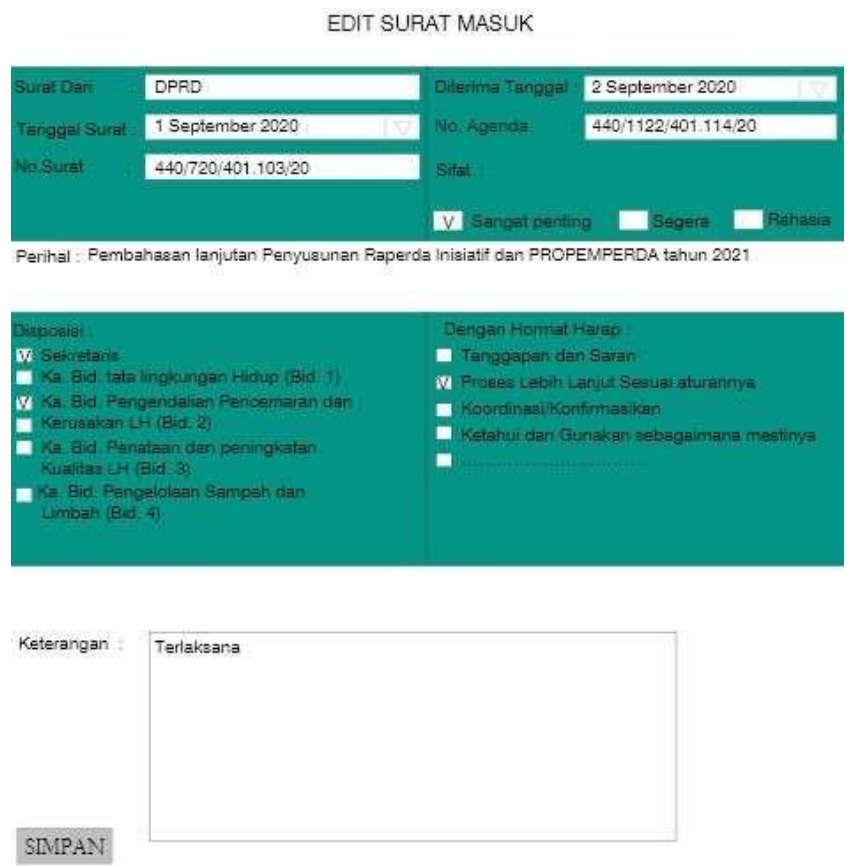

Gambar 8. Form Edit Surat Masuk

\section{Form Surat Keluar}

Sama seperti form surat masuk, halaman utama surat keluar juga setelah user berhasil login petugas atau user tersebut langsung bisa menginputkan surat masuk dan terdapat 4 bidang yang dapat dipilih. Namun sedikit berbeda penginputannya dengan surat masuk.

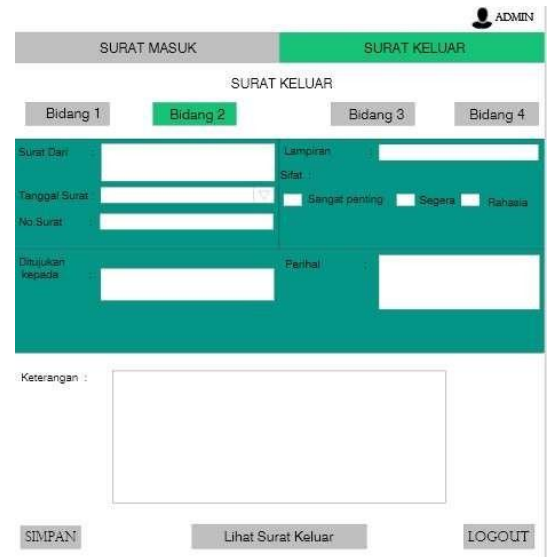

Gambar 9. Form Surat Keluar

Volume 6 Nomor 1 Maret 2021, PILAR TEKNOLOGI | 40 
6. Form Tabel Laporan Surat Keluar

Form ini adalah tabel dari semua hasil penginputan di surat keluar.

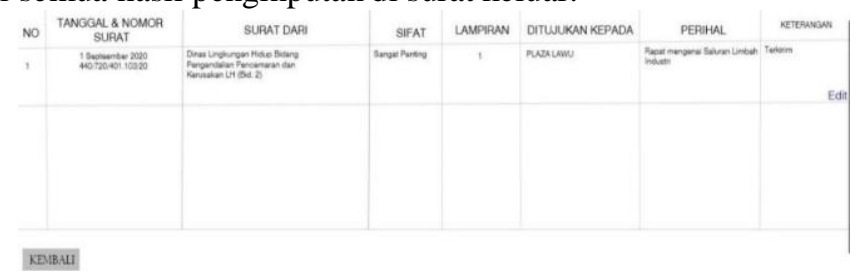

Gambar 10. Form Tabel Laporan Surat Masuk

\section{Form Menu Edit Surat Keluar}

Sama halnya dengan form menu edit surat masuk, pada halaman tabel surat keluar juga terdapat menu edit yang digunakan untuk memperbaiki surat keluar jika ada kesalahan penginputan.

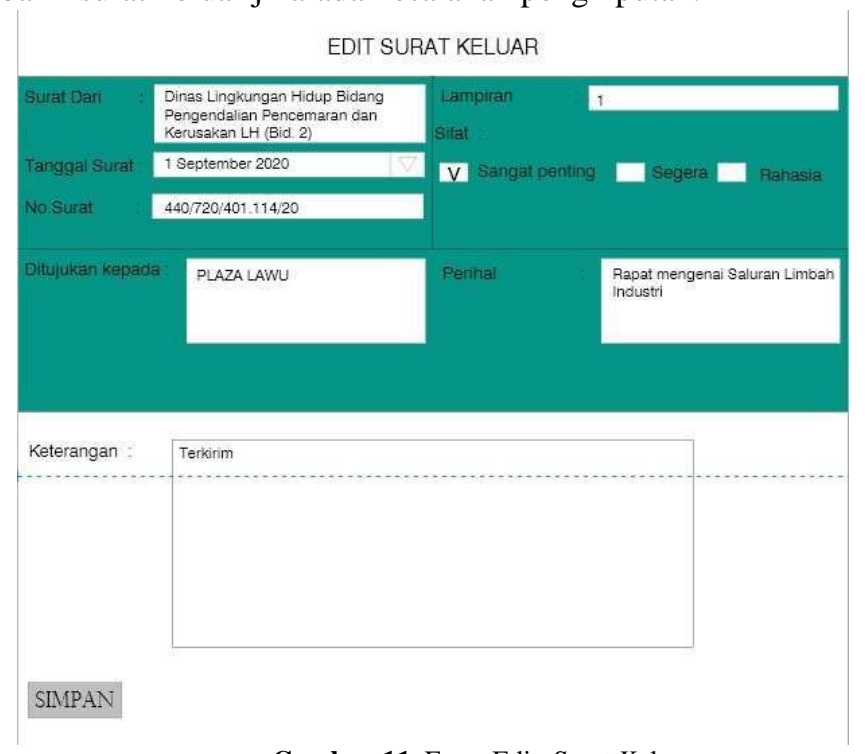

Gambar 11. Form Edit Surat Keluar

\section{IV.KESIMPULAN}

Kesimpulan dalam penelitian ini yaitu Sistem Informasi arsip surat akan membantu mempermudah admin dalam mengelola arsip surat dengan cepat, tepat dan efisien dan Tersedianya laporan surat masuk dan keluar dapat mempermudah admin dalam melihat arsip surat Dengan adanya perancangan prototype ini diharapkan tidak ada lagi masalah dalam pencatatan atau pengelolaan surat masuk dan surat keluar di Dinas Lingkungan Hidup Kota Madiun.

\section{DAFTAR PUSTAKA}

Bentley, Whitten. (2019). Systems Analysis and Design Methods Editions. MA:McGraw-hill Irwin. Boston

Syamsiah. "Perancangan Flowchart dan Pseudocode Pembelajaran Mengenal Angka Dengan Animasi Untuk Anak Paud Rambutan" STRING (Satuan Tulisan Riset dan Inovasi Teknologi), Vol.4 No. 1 Agustus 2019.

O. Fajarianto, "Prototype Pelayanan Akademik Terhadap Komplain Mahasiswa Berbasis Mobile", J. Lentera Ict, vol.3, no.1, pp. 54-60, 2017.

Nur ID, Miftachul MA, Sandyca RN. 2019. "Analisis Perancangan Sistem Informasi Pengarsipan dan Disposisi Surat Berbasis Chronological Filling System". Seminar Santika. September 2019. Pp.4-5.

Hisyam Wahid Luthfi dan Berliana Kusuma Riasti., 2015. ”Sistem Informasi Perawatan Dan Inventaris Laboratorium Pada Smk Negeri 1 Rembang Berbasis Web". Speed-Sentra Penelitian Engineering dan Edukasi, 3(3).pp.69-77. 